\title{
Auxílio emergencial e trabalho do Serviço Social no contexto da Covid-19
}

Emergence aid and Social Work actions in the context of Covid-19

\author{
Maria Ozanira da Silva e Silva* \\ Salviana de Maria Pastor Santos Sousa** \\ Valéria Ferreira Santos de Almada Lima***
}

\begin{abstract}
Resumo - O artigo, referenciado em estudos e pesquisas desenvolvidas pelas autoras, aborda o contexto socioeconômico e político em tempos da Covid-19 no Brasil para tratar da transferência monetária como como medida privilegiada para reduzir o avanço da pobreza e das desigualdades sociais; considera o Benefício Emergencial como produto de pressões da sociedade, dos políticos e dos estudiosos da temática em prol da proteção social. Aborda ainda o trabalho do Serviço Social na atualidade da Política de Assistência Social junto ao Auxílio Emergencial. A principal conclusão destaca a prevalência dos programas de transferência de renda para proteção social no Brasil pós 1990 e a contribuição relevante da Política de Assistência Social na implementação do Benefício Emergencial.

Palavras-chave: Desigualdades. Covid-19. Programas de Transferência de Renda. Proteção Social. Serviço Social.
\end{abstract}

\begin{abstract}
The article is referenced in studies and research developed by the authors. It addresses the social, economic and political context of Covid-19 in Brazil, in order to develops a discussion about the prevalence of monetary transfers as political modality to decrease the advance of poverty and the social inequalities; focus on the Emergence Aid Program as product of pressions of the society, politicians and studious of the thematic of the social protection. The article even approaches the actions of Social Work in the nowadays of the Social Aid Policy on the Emergence Aid. The main conclusion emphasis the prevalence of the income transfer programs for social protection in Brazil post 1990 and the great contribution of the Social Aid Policy in the implementation of the Emergence Aid.
\end{abstract}

Keywords: Inequalities. Covid-19. Income Transfer Programs. Social Protection. Social Work.

\footnotetext{
* Doutora em Serviço Social. Professora do Programa de Pós-Graduação em Políticas Públicas (PPGPP) da Universidade Federal do Maranhão (UFMA). Coordenadora do Grupo de Avaliação e Estudo da Pobreza e de Políticas direcionadas à Pobreza (Gaepp) da mesma universidade. Pesquisadora, nível IA, do CNPq. E-mail: maria.ozanira @gmail.com.ORCID: https://orcid.org/0000-0003-0421-9934.

** Doutora em Políticas Públicas; professora do PPGPP/UFMA. Pesquisadora do Gaepp. Pesquisadora, nível II, do CNPq. E-mail: sousa.salviana@ufma.br. ORCID: https://orcid.org/0000-0002-9432-9776.

*** Doutora em Políticas Públicas; professora do PPGPP/UFMA; pesquisadora do Gaepp. Pesquisadora, nível II, do CNPq. E-mail: valmadalima@gmail.com.br.ORCID: https://orcid.org/0000-0002-6635-427X.
} 


\section{Introdução}

O presente texto reflete sobre o crescimento das desigualdades e da pobreza no contexto da emergência da Covid-19 no Brasil. Todavia, o entendimento é de que as desigualdades e a pobreza se encontram no processo de formação da sociedade brasileira, marcado por projetos econômicos e sociopolíticos presentes no desenvolvimento do capitalismo no país. Por conseguinte, a pandemia da Covid-19 expressa um momento histórico

[...] conservador e autoritário, profundamente submetido aos interesses do capitalismo financeiro internacional, com verdadeiro desrespeito a princípios democráticos que vinham regendo a sociedade brasileira, cuja consequência de maior destaque é um amplo retrocesso dos direitos sociais e trabalhistas, além de desativação e redução de programas sociais relevantes para a população pobre. (SILVA; LIMA, 2017, p. 15).

Nesse contexto, são desconstruídos direitos historicamente conquistados com a desfiguração da seguridade social instituída pela Constituição Federal de 1988, de modo que as populações que vivem em situação de pobreza tendem a ser responsabilizadas e criminalizadas pelas carências a que são submetidas. São segmentos de trabalhadores, na sua maioria, constituídos por mulheres e homens negros, sem contrato formal com o mercado de trabalho e, consequentemente, carentes de proteção social.

Com a crise do capitalismo e as reformas que se vêm instituindo no país, a essas populações somam-se novos grupos. Esses grupos, de acordo com o Centro de Estudos da Metrópole da Faculdade de Filosofia, Letras e Ciências Humanas da USP (2020), são compostos por mulheres e homens brancos, detentores de curso superior completo e que vinham mantendo vínculos de trabalho mais estáveis, atuando em serviços não essenciais ou em setores essenciais mais economicamente afetados. No contexto da pandemia, o mesmo estudo indica a existência de 75,5 milhões de pessoas, que representam $81 \%$ da força de trabalho no Brasil, impactadas por algum tipo de vulnerabilidade em decorrência da Covid-19. Essa realidade evidencia o tamanho da pobreza e das desigualdades no Brasil contemporâneo, e esse é o público-alvo do Auxílio Emergencial.

Para responder ao proposto, o texto constitui-se de três itens, além da introdução e da conclusão. No primeiro, contextualiza o momento atual de emergência da Covid-19 no Brasil. Articula a grave situação sanitária com os reflexos da estratégia ultraliberal de que se vem alimentando a ordem capitalista para responder à sua atual crise, expressa, sobretudo, através do aumento da desigualdade social, da pobreza e do desmonte de direitos sociais historicamente conquistados. O segundo item apresenta uma discussão sobre a prevalência da transferência monetária como modalidade 
de atenção social direcionada a mitigar o avanço da pobreza e das desigualdades, como é o caso do Auxílio Emergencial. Este é problematizado no seu conteúdo, nos critérios de acesso e exigências estabelecidas e nos limites e problemas observados na sua implementação. O terceiro item aborda o Serviço Social como parte das equipes de trabalho situadas no campo da política de assistência social, articulando a atuação desses profissionais na implementação do Auxílio Emergencial.

\section{Contexto socioeconômico e político em tempos de pandemia da Covid-19 no Brasil}

O fio condutor que orienta o presente item parte do entendimento de que a pandemia da Covid-19 vem contribuindo para explicitar a pobreza e as desigualdades sociais como marcas do processo de formação da sociedade brasileira. Do ponto de vista histórico, essa pobreza é datada e situada, expressão das desigualdades sociais, assim como os sempre insuficientes recursos e serviços voltados para seu enfrentamento, expressos em gramáticas políticas tais como o clientelismo e o assistencialismo. Elas têm sido partes constitutivas do processo de formação da sociedade brasileira, da mesma forma que também o são a luta social pela ruptura e pela construção de uma sociedade mais igualitária.

Cumpre, entretanto, ressaltar que o Brasil, na virada para o século XXI, bem como outros países da América Latina - grande parte deles sob o comando de governos progressistas -, vivenciaram uma importante inflexão. Essa mudança é marcada pela retomada do crescimento econômico, propiciada por um contexto internacional favorável e pela melhoria dos indicadores sociais, sobretudo os relacionados ao mercado de trabalho, à pobreza e à desigualdade (LIMA, 2013). Não obstante, na segunda década dos anos 2000, pôde-se identificar, principalmente a partir de 2013, no primeiro mandato da então presidenta Dilma Roussef, uma nova inflexão na economia brasileira, com rebatimentos negativos sobre o mercado de trabalho.

Sobrepondo-se a esse contexto, a partir do início de 2015, no segundo mandato da presidenta Dilma Roussef, ocorreu uma profunda crise política e institucional com visível polarização da sociedade em torno de projetos político-ideológicos distintos e forte avanço do conservadorismo. Essa crise culminou, em 2016, na aprovação pelo Congresso Nacional do impeachment da presidenta Dilma Roussef. O governo foi, então, assumido pelo vice-presidente da República Michel Temer, do PMDB, abrindo espaço para a vitória de um projeto conservador que punha em xeque importantes avanços experimentados pelo país, sobretudo na esfera social, ao longo da primeira década de 2000, mediante rigorosos cortes de recursos, especialmente na área social. 


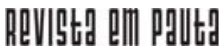

\} AUXÍlIO EMERGENCIAL - SILVA, M. O. S.; SOUSA, S. M. P. S.; LIMA, V. F. S. A. \}

DOI: $10.12957 /$ REP.2021.60299

Como rebatimento desse contexto de acirramento da crise político-institucional, de ajuste fiscal e de deterioração das condições macroeconômicas sobre os indicadores do mercado de trabalho, destaca-se a elevação da taxa média de desocupação, que chegou a 11,5\% em 2016, saltando para 13,1\% em 2017 (LIMA; MORAES; SILVA, 2017; IBGE, 2017). A piora acentuada no mercado de trabalho apontava também para a deterioração da qualidade do emprego. De fato, conforme demonstram os dados PNAD Contínua, o percentual de trabalhadores ocupados inseridos no mercado de trabalho formal, após uma tendência crescente registrada até 2014, caiu sucessivamente até 2019, tendo atingido, neste ano, o índice de 58,9\%, contra o patamar de $81,5 \%$ alcançado em 2014 , o maior observado desde 2012. Concomitantemente, os trabalhadores ocupados informais, que correspondiam a $18,5 \%$ do total de ocupados em 2014, passaram a representar $41,1 \%$ em 2019, expressando o maior índice de informalidade observado desde 2012 (IBGE, 2015).

Essa expressiva deterioração dos indicadores de mercado de trabalho impactou negativamente os índices de pobreza e de extrema pobreza no período em análise, conforme se pode depreender a partir dos dados da PNAD Contínua. De fato, o índice de extrema pobreza (percentual de pessoas com renda domiciliar per capita de até um quarto do salário-mínimo mensal), que, conforme exposto anteriormente, vinha caindo desde o início dos anos 2000, permaneceu em queda até 2014. A partir de então, voltou a subir, atingindo o patamar de 10,6\% em 2018, contra 8,0\% em 2014, menor índice da série iniciada em 2012. Já o índice de pobreza (percentual de pessoas com renda domiciliar per capita de um quarto até meio saláriomínimo mensal), que também vinha caindo até 2014, quando alcançou $17,0 \%$ voltou a crescer. Chegou a 18,5\% em 2016, embora tenha experimentado uma ligeira queda em 2017 e 2018 (17,7\% e 17,6\%, respectivamente), sem, contudo, recuperar o patamar atingido em 2014 (17,0\%) (IBGE, 2020).

Cumpre ressaltar que a eleição de Jair Bolsonaro, em 2018, e sua posse como presidente da República, em 2019, representou o aprofundamento, no Brasil, de tendências autoritárias, fascistas, ultraconservadoras e ultraliberais, que passaram a pôr em xeque importantes conquistas civilizatórias da sociedade brasileira em todos os campos das políticas públicas. É, portanto, nesse contexto de avanço do conservadorismo, de ataque aos direitos sociais, de crescente insegurança do trabalho e de aumento da pobreza que o Brasil enfrenta as consequências nefastas da pandemia da Covid-19 sobre os indicadores sociais.

Com efeito, segundo boletim da Fundação Getúlio Vargas (IBRE, 2020), o impacto esperado da crise desencadeada pela pandemia da Covid19 chega a níveis não vistos anteriormente na história recente do mercado de trabalho brasileiro. A taxa de desocupação projetada para 2020 é de $17,8 \%$, o que corresponde a uma taxa 6 pontos percentuais maior do que 
a de 2019. Com isso, a massa de rendimentos efetivos do trabalho está projetada para cair $14,4 \%$, puxada por uma queda de $6,6 \%$ da população ocupada, e de $8,6 \%$ da renda do trabalho efetiva, a qual em média fechará o ano no nível de $\mathrm{R} \$ 2.206,00$ mensais, frente a $\mathrm{R} \$ 2.413,00$ no ano anterior. Assim, a massa de rendimento do trabalho chega a ser $3,2 \%$ menor do que o início da série histórica, em 2012, e também o mais baixo.

Face ao exposto, vislumbra-se um cenário pessimista quanto aos efeitos econômicos e sociais da atual crise ocasionada pela pandemia da Covid-19, sobretudo considerando-se as particularidades de sua forma de enfrentamento no Brasil. Se se confirmar a contração do PIB entre 5 e 7\% em 2020, a economia brasileira, que já se encontrava cerca de $4 \%$ inferior ao nível de atividade de 2014, iniciará o ano de 2021 podendo equivaler a menos de $90 \%$ do verificado há seis anos. Além disso, deve-se considerar que o governo federal anunciou a intenção de retomar, a partir de 2021, o normal econômico verificado antes da pandemia da Covid-19, ou seja, variação do PIB entre 1,1\% e 1,3\% entre os anos de 2017 e 2019. Sendo esse índice de fato alcançado, o Brasil retomará o patamar do PIB de 2014 somente no ano de 2030, e o PIB per capita no ano de 2037. Em síntese, trata-se da mais grave crise econômica já registrada pela trajetória histórica do capitalismo brasileiro (SILVA, 2020b).

Com a ocorrência da pandemia da Covid19, enquanto o país passou a vivenciar incertezas relacionadas à origem do vírus, à forma e ao tempo das restrições, às interdições e racionamentos, assim como às consequências políticas, econômicas, nacionais e internacionais provocadas em função dos confinamentos (MORIN, 2020), o governo federal se alinhou ao restrito bloco de governantes que, ao redor do planeta, nega a virulência da enfermidade. De fato, cumpre ressaltar a postura de descaso assumida pelo governo Bolsonaro, face ao drama sanitário e social sem precedentes vivenciado pelo mundo e, particularmente, por um país como o Brasil, já historicamente marcado pela desestruturação do seu mercado de trabalho e por elevados índices de pobreza e desigualdade.

\section{A prevalência da transferência monetária para proteção social em tempos de pandemia da Covid-19: pontuando e problematizando o Auxílio Emergencial}

No presente item, a centralidade da temática abordada tem como foco o Benefício Emergencial, programa de transferência monetária do governo federal, instituído em abril de 2020 como medida de política social para atenuar as consequências da profunda crise econômica decorrente da pandemia da Covid-19 sobre os mais pobres, principalmente os desempregados e os trabalhadores do setor informal sem proteção social. Partimos da construção de um referencial que fundamenta a análise desenvolvida, 
\} AUXÍlIO EMERGENCIAL - SILVA, M. O. S.; SOUSA, S. M. P. S.; LIMA, V. F. S. A. \}

DOI: $10.12957 /$ REP.2021.60299

seguindo com a apresentação, caracterização e problematização do Benefício Emergencial.

\subsection{O referencial norteador para uma leitura problematizadora do Benefício Emergencial}

Falar de prevalência da transferência monetária para proteção social no Brasil remonta aos anos de 1990, mais especificamente a partir de 1995, quando se iniciou um amplo processo de criação e implementação de programas de transferência monetária em nível municipal, genericamente denominados Programas de Renda Mínima e Bolsa Escola. Esse processo é seguido com a criação de programas estaduais e federais, sendo considerada, em 2001, a constituição do que foi denominado de Rede de Proteção Social, cuja maior expressão foi a criação do Bolsa Família, em 2003, que em 2006 já se encontrava implantado em todos os municípios brasileiros, atendendo a um público sem precedente na história dos programas sociais no Brasil (SILVA; YAZBEK, GIOVANNI, 2012).

É fundamental considerar que os programas de transferência monetária não são orientados somente por matizes do pensamento progressista, mas são também largamente influenciados por matizes de caráter liberal e conservador. Daí o porquê de a função precípua das práticas desenvolvidas ter sido mitigar a pobreza e legitimar governos, embora atendam também a necessidades básicas de seu público beneficiário, ao mesmo tempo em que atendem aos interesses do capital, pelo amplo potencial de dinamizar as economias. Essas funções ficam sobejamente demonstradas com a implementação do Auxílio Emergencial enquanto programa altamente focalizado.

Nesse aspecto, entendemos como programas focalizados aqueles que incluem alguns ou variados critérios para acesso, com maior destaque à renda, sendo a população-alvo os pobres e extremamente pobres, indivíduo ou família. A idade é outro critério destacado, por esses programas tenderem a priorizar determinadas faixas etárias. São, por vezes, também considerados critérios de acesso a esses programas a localização da moradia (SILVA, 2020a). Seja qual for o critério para inclusão, sua função é atenuar a pobreza e atender a situações emergenciais.

Outra modalidade de programas de transferência monetária é a renda básica universal. Esta apresenta dois qualificadores fundamentais: universalidade, por destinar-se a todos os residentes de uma comunidade, Estado ou país; e incondicionalidade, por independer de qualquer critério para acesso, ou seja, não adota qualquer teste de meios. É uma transferência monetária, periódica, individual, universal e incondicional (REDE BRASILEIRA DE RENDA BÁSICA - RBRB, [2019?]). Assim concebida, a renda bá- 


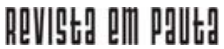

\} AUXÍLIO EMERGENCIAL - SILVA, M. O. S.; SOUSA, S. M. P. S.; LIMA, V. F. S. A. \}

DOI: $10.12957 /$ REP.2021.60299

sica universal propõe-se a distribuir a riqueza socialmente produzida, buscando a diminuição da desigualdade e o alcance da justiça social ${ }^{1}$.

Merece ainda considerar que, na ampliação do debate recente sobre programas de transferência monetária, quer seja no Brasil, quer em outros países, são identificadas confusões conceituais e de caráter teóricoideológico que precisam ser aclaradas. Trata-se, por exemplo, de frequentes imprecisões conceituais sobre a diversidade de propostas em circulação e a expressão de um aparente consenso teórico-ideológico entre os diferentes defensores dessas propostas e programas. Nesse aspecto, é importante levar em conta a inexistência da neutralidade e de uma perspectiva consensual. Temos o entendimento de que toda proposta e todo programa social fundamenta-se numa determinada concepção de mundo e, especificamente, numa determinada concepção de pobreza; ou seja, cada proposta, cada programa tem como fundamento uma concepção teórica, política e ideológica (SILVA et al., 2020).

É com essas referências que nossa análise e problematização sobre o Auxílio Emergencial é, a seguir, desenvolvida.

\subsection{O Auxílio Emergencial}

O Auxílio Emergencial é um programa de transferência monetária focalizado sem condicionalidades. Foi instituído pela Medida Provisória n. 936, de 1 de abril de 2020, tendo como objetivo atenuar a situação decorrente da elevação do desemprego, do trabalho informal precarizado e da pobreza no contexto da pandemia da Covid-19.

É um programa com duração limitada, inicialmente previsto para três meses (abril, maio e junho). Teve uma segunda extensão para os meses de julho, agosto e setembro, seguida de uma terceira extensão até dezembro de 2020. Para sua formulação, contou com intensa pressão de movimentos de várias associações civis, economistas, cientistas sociais e de pessoas afetadas pela pobreza e pelo desemprego (RBRB, [2019?]). A proposta inicial do governo foi disponibilizar um benefício monetário mensal de $R \$ 200,00$, recebendo forte pressão do legislativo, com apoio de movimentos sociais, para elevação desse do valor, que terminou alcançando $R \$ 600,00$. Todavia, na terceira ampliação temporal, o valor foi fixado em $\mathrm{R} \$ 300,00$.

Trata-se de um programa com muitos critérios para acesso ${ }^{2}$, direcionando-se inicialmente para microempreendedores individuais; contri-

\footnotetext{
${ }^{1}$ Sobre concepções e práticas de renda básica universal, veja Torry (2019); e sobre a experiência brasileira, veja, na obra citada, o capítulo de Maria Ozanira da Silva e Silva e Valéria Ferreira Sando de Almada Lima denominado Citizen's Basic Income in Brazil: from Bolsa Família to pilot experiences.

${ }^{2}$ A existência de critérios para acesso aos programas de transferência de renda condicionados, via de regra, são obstáculos para inclusão do público-alvo determinado por esses programas. Isso tem ocorrido em ampla dimensão no caso do Auxílio Emergencial, conforme tem revelado o Tribunal de Contas da União (TCU) e os Tribunais de Contas dos Estados, com ampla divulgação pela imprensa.
} 


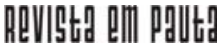

\} AUXÍLIO EMERGENCIAL - SILVA, M. O. S.; SOUSA, S. M. P. S.; LIMA, V. F. S. A. \}

DOI: $10.12957 /$ REP.2021.60299

buintes individuais ou facultativos do Regime Geral da Previdência Social; trabalhadores informais inscritos no Cadastro Único (Cadúnico) do governo federal ou em aplicativo da Caixa Econômica Federal (CEF); e beneficiários do Bolsa Família. Na proposta inicial, o público-alvo deveria atender aos seguintes critérios para acesso: ter mais de 18 anos; renda per capita familiar de meio salário-mínimo ou renda familiar mensal total de até três saláriosmínimos; e não ter tido rendimentos tributáveis em 2018, devendo incluir, no máximo, duas pessoas por família, sendo que mulheres chefes de família monoparental têm direito a receber o benefício em dobro, ou seja, R\$ 1.200,00 mensais ${ }^{3}$.

Todavia, na última ampliação de tempo, que estendeu o Benefício Emergencial até dezembro de 2020, foram adotados critérios mais restritivos para o acesso do público-alvo ao benefício, tais como: exclusão de preso em regime fechado e de brasileiros residentes no exterior; sobre o Imposto de Renda da pessoa física foi considerada a declaração de 2020, com exclusão dos que receberam rendimentos isentos, não tributáveis ou tributáveis na fonte acima de $R \$ 40.000$, ficando ainda de fora pessoas incluídas na declaração como dependentes; foi retirado do auxílio quem tinha, em 31 de dezembro de 2019, a posse ou a propriedade de bens e direitos em valor de $\mathrm{R} \$ 300 \mathrm{mil}$, sendo ainda excluído quem adquiriu vínculo de emprego com carteira assinada; quem obteve benefício previdenciário ou assistencial, como aposentadoria, Benefício de Prestação Continuada (BPC) ou pensão por morte. Foi, porém, mantida a acumulação do benefício para mulher chefe de família; contudo, ela deveria ser a única a receber o auxílio na família ${ }^{4}$.

É importante, ainda, destacar que o Auxílio Emergencial apresenta recorrentes problemas tanto para o acesso como para a implementação. $O$ Centro de Estudos da Metrópole da FFLCH da USP (2020) indica que 7,4 milhões de pessoas elegíveis para receber o auxílio vivem em domicílios que não têm acesso à internet. Ademais, esse público apresenta, em grande parte, dificuldades para o manejo do aplicativo.

Em relação à implementação do benefício, foi demonstrada a improvisação e a falta de planejamento tanto na seleção dos beneficiários, como na distribuição do benefício. Em consequência, foi sobejamente divulgada geração de aglomerações, contribuindo para ampliação de contágio da Covid-19; dificuldades de acesso às agências pagadoras; distorções na concessão e denúncia de uso indevido do auxílio; falta de transparência na seleção do público demandante; informações desencontradas; atrasos nos pagamentos; e demora no processo de análise das solicitações. Ademais, o

\footnotetext{
${ }_{3}^{3}$ Posteriormente, o público-alvo do Auxílio Emergencial foi ampliado pelo Projeto de Lei no 873/2020, do Senador Randolfe Rodrigues (Rede-AP), com a inclusão de catadores de material reciclável, seringueiros, taxistas, mototaxistas, motoristas de aplicativos, manicures, diaristas e pescadores artesanais, permitindo também que mães adolescentes, mesmo com menos de 18 anos, recebam o benefício.

${ }^{4}$ As informações sobre o público-alvo e os critérios do Benefício Emergencial encontram-se no site do Ministério da Cidadania (disponível em: https://www.gov.br/cidadania/pt-br/servicos/auxilio-emergencial).
} 


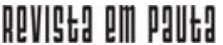

\} AUXÍLIO EMERGENCIAL - SILVA, M. O. S.; SOUSA, S. M. P. S.; LIMA, V. F. S. A. \}

DOI: $10.12957 /$ REP.2021.60299

aparato institucional já consolidado no Cadúnico, que dispõe de 11.908 postos em todos os municípios e experiência de 17 anos no Bolsa Família, foi ignorado, o que reforçou a improvisação e os problemas na implementação do auxílio (SILVA et al., 2020; SILVA, 2020a; 2020b).

Entendemos que muitos dos problemas pontuados na implementação do Auxílio Emergencial poderiam ter sido evitados ou reduzidos com a instituição de uma rede descentralizada de distribuição da transferência monetária. Essa seria capaz de minimizar os sacrifícios e os desrespeitos sofridos pelo público beneficiário, além de inserção de profissionais com experiência no planejamento e na implementação de programas sociais.

Em contraposição aos problemas citados, o Benefício Emergencial apresenta contradições e positividades tais como: atendimento massivo no contexto de avanço da pobreza, alcançando cerca de $70 \mathrm{mi}-$ Ihões de pessoas; não ter condicionalidades; ampliar o espaço para a proteção social por meio de transferência monetária e, contraditoriamente, explicitou o tamanho da pobreza no Brasil, impulsionando o debate sobre programas de transferência de renda condicionados e Renda Básica Universal. (SILVA et al., 2020, p. 19).

O Benefício Emergencial criado em 2020 foi interrompido durante os meses de janeiro, fevereiro e março de 2021. Este foi o período da denominada segunda onda da Covid-19, com ampliação do declínio da economia já fragilizada e aprofundamento do desemprego, da pobreza, da extrema pobreza e da fome, que assumem patamares insustentáveis, motivando a ampliação de pressões sociais, inclusive do Parlamento Brasileiro, para recriação do Benefício Emergencial.

Sob pressão, o governo federal instituiu a Medida Provisória N. 1.039 de 18 de março de 2021 da Presidência da República/SecretariaGeral/Subchefia para Assuntos Jurídicos, recriando O Benefício Emergencial, a princípio, para o período de abril a julho de 2021.

A análise da Medida Provisória explicita a criação de um benefício altamente restritivo, em termos quantitativos, além da indicação de um número ainda mais elevado de critérios, não para inclusão, mas de exclusão, reduzindo de 68 milhões de pessoas atendidas em 2020, para um públicoalvo de 40 milhões de pessoas. Os critérios de exclusão adotados ampliaram a focalização conservadora que já vinha sendo adotada, por indicar amplo espectro de critérios, como mencionado, focados não na inclusão, mas na exclusão. Entre os critérios determinados pela Medida Provisória, tem-se: não pagamento ao trabalhador com vínculo empregatício formal ativo; que receba benefício previdenciário, assistencial ou trabalhista; com renda familiar per capita acima de meio salário-mínimo; que seja membro de família com renda total acima de três salários-mínimos; que residam no exterior; tenha recebido, em 2019, rendimentos tributáveis acima de R \$ $28.559,70$; tenha posse ou propriedade de bens ou direitos no valor de R \$ 
3000,00, em 31 de dezembro de 2019; tenha recebido rendimentos isentos, não tributáveis ou tributados exclusivamente na fonte, com somatório superior a $\mathrm{R} \$ 40.000,00$; tenha sido incluído, em 2019, como dependente de declarante sobre a Renda de Pessoa Física; esteja preso em regime fechado ou receba auxílio reclusão; tenha menos de 18 anos, exceto no caso de mães adolescentes, sendo o benefício limitado a uma pessoa por família. Ademais, o valor monetário mensal do benefício foi reduzido pela metade: para mulheres provedoras de família monoparental o valor mensal ficou em R \$375,00; o valor médio do benefício foi limitado a $R$ \$ 250,00 e o valor para família unipessoal ficou em $\mathrm{R} \$ 150,00$, valores insuficientes para aquisição, se quer, da cesta básica.

Entendemos, ainda, que o Auxílio Emergencial se desenvolve num contexto de repressão e criminalização dos movimentos sociais populares, bem como de responsabilização dos pobres por sua situação de pobreza. Ademais, busca mitigar uma situação estrutural decorrente da forma como a sociedade se organiza para produção e distribuição da riqueza socialmente produzida. Mais ainda, trata-se de um contexto em que os interesses políticos estão sempre presentes; em que os programas sociais, entre estes o Auxílio Emergencial, são moeda para aprovação política com fins eleitoreiros.

Essa é uma realidade que precisa ser superada pela luta organizada em direção à construção de uma sociedade plural e respeitada nas suas minorias e nos direitos humanos, na busca da igualdade social.

\section{O trabalho do Serviço Social na atualidade da política de assistência social: atuação junto ao Auxílio Emergencial}

No desenvolvimento do presente item, partimos da constatação de que a pandemia de Covid-19 vem contribuindo para explicitar a ampliação da pobreza e das desigualdades sociais, permitindo refletir sobre a configuração da política de assistência social e sobre o exercício profissional dos/as assistentes sociais. De fato, mesmo considerando o grande potencial de disseminação do vírus e abstraindo-se os grupos que não incorporam como necessárias as duas orientações básicas da Organização Mundial da Saúde (OMS) - higienizar as mãos e manter o distanciamento social -, imensos contingentes populacionais no país não o fazem por viverem em moradias que não permitem qualquer privacidade. Além disso, são limitadas por privações de toda ordem, como precariedade do abastecimento de água, do esgotamento sanitário e de serviços de manejo e drenagem de resíduos sólidos e águas pluviais (SOUSA, 2020).

A Carta Constitucional de 1988 traduziu em balizas regulatórias parte das demandas da sociedade brasileira com o reconhecimento e a relevância de direitos sociais. Embora expresse, tão somente, a vitória da regulação social na tensão dialética entre esse movimento e o da emanci- 
pação social na política de direitos humanos, que passou a se desenvolver a partir de meados do século XX, base da configuração do Estado de BemEstar Social, é considerado um texto avançado para o período. Isto porque foi criado na contramão das mudanças conservadoras que já ocorriam na ordem capitalista e que confrontavam os princípios de justiça e solidariedade com os de competição e eficiência, base da ofensiva neoliberal no mundo.

Nesse sentido, a Carta de 1988 possibilitou a ocorrência de mudanças normativas que se refletiram na criação de sistemas protetivos relevantes no campo da seguridade social, como o Sistema Único de Saúde (SUS) e o Sistema Único de Assistência Social (Suas). Esses, coerentes com a proposta socialdemocrata, foram alocados como respostas ao dilema ético-político da justiça, tendo subjacente o primado do público e o equilíbrio de forças sociais antagônicas, a partir de normas e caráter geral.

O Suas institucionaliza as medidas de proteção social regulamentadas pela Lei Orgânica da Assistência Social (Loas), em 1993, tendo como suporte uma nova concepção de assistência social no Brasil. Passa a transitar no campo dos direitos, sem romper com a perspectiva histórica que conformou essa política no âmbito do não direito. Isso porque a unidade de atenção era o pobre, trabalhador casual e destituído, pessoa sem recursos materiais, necessitada e, muitas vezes, entendida como acomodada, inerte em relação à mudança da sua própria condição, dependente de ajuda, não cidadão, enfim ${ }^{5}$.

O Auxílio Emergencial, apresentado no item 2 do presente texto enquanto suporte financeiro originário do governo federal e operado pela Caixa Econômica Federal (CEF), não foi pensado como ação destinada ao fortalecimento do Suas (YAZBEK; FALEIROS, 2020) ${ }^{6}$. Sua natureza, contudo, faz com que rebata diretamente sobre o campo da assistência social porque, destinado a reduzir impactos socioeconômicos da pandemia, constitui-se em lenitivo em momento crucial de perda de emprego e disseminação ampla da enfermidade, agregando-se a outras formas de transferência de renda em curso, como o Bolsa Família.

Impacta também o trabalho dos/as assistentes sociais, uma vez que os receptores do auxílio são os mesmos que demandam o conjunto de programas, projetos, serviços e benefícios voltados à proteção social e ao atendimento de necessidades da população usuária dessa política: trabalhadoras/es informais, trabalhadoras/es sem-teto, moradoras/es das periferias urbanas, imigrantes sem registro, pessoas com deficiências, idosas/os, segmentos populacionais mais vulneráveis à Covid-19. São grupos que precisam usar a criatividade para inventar formas de sobrevivência.

Tendem a ser criminalizados pela associação aos estereótipos criados no contexto da obsessão securitária que marca a modernidade brasileira,

${ }^{5}$ Para refletir sobre o tema, consultar Raichelis R. et al (2019).

${ }^{6}$ Conferir sobre o tema em Kilduff e Silva (2019). 
em razão da sua condição de moradia, raça/etnia, orientação sexual e escolaridade. Passam despercebidos nos gabinetes em que são tomadas as grandes decisões, e parte deles tende a ficar invisível no processo gestionário das políticas públicas. São demandantes marcados pela insatisfação, cansaço e revolta, que convivem em espaços territoriais atravessados por violência, abandono, descaso e precariedade.

Em atendimento às exigências do Código de Ética da profissão, o trabalho profissional dos/as assistentes sociais encaminha-se no sentido de desconstruir gramáticas políticas, ainda prevalecentes no Brasil, entre as quais a da fulanização na prestação dos serviços sociais ${ }^{7}$, do clientelismo, do mandonismo, do primeiro-damismo. Ao mesmo tempo, enfrentam desafios - como o tecnicismo, que valoriza modelos de administração empresarial e controle social como medida da eficiência governamental.

Nesse sentido, as orientações técnicas elaboradas pelo Conselho Federal em Serviço Social (CFESS) e pelo Conselho Regional de Serviço Social (Cress), analisadas por Negri, Santos e Krüger (2020), apontam que se impõe, no cenário da pandemia e de usufruto do Auxílio Emergencial, a necessidade de aprofundar o conhecimento sobre a base de dados disponível no Cadúnico. O objetivo é a construção de aparatos tecnológicos reforçando as ações de resistência e ampliando serviços socioassistenciais, a fim de garantir as seguranças afiançadas pela política nacional de assistência social, articulando-se às políticas de assistência social, de previdência e de saúde.

Pelo exposto, embora reconheçamos que os recursos repassados pelo Auxílio Emergencial, nesse momento de disseminação da Covid-19, sejam fundamentais para os beneficiados, são irrelevantes em seu conjunto. Trata-se, porém, de um espaço/tempo que permite refletir sobre as condições objetivas de grandes massas populacionais no Brasil que carecem de assistência.

Enfim, sobre o trabalho do Serviço Social no âmbito do Auxílio Emergencial, há que se destacar dois aspectos relevantes. O primeiro é a frequente recorrência à ajuda de profissionais nos Centros de Referências da Assistência Social (Cras) para preenchimento do aplicativo da CEF. Além disso, também a contribuição dos profissionais da assistência social aos beneficiários do auxílio, prestando-lhes orientações e apoio em relação aos problemas enfrentados no processo de seleção e durante a implementação, mesmo o governo federal tendo desconsiderado o potencial e a experiência desses profissionais, conforme tratado no item anterior deste artigo.

O segundo é a própria configuração do exercício laboral das equipes de trabalho, que se desenvolve, quase sempre, em situação de

${ }_{7}^{7}$ A expressão é utilizada por Faleiros (2014). 
ansiedade permanente ${ }^{8}$. Isso ocorre tanto pela incapacidade de atender a demandas que denunciam a redução sistemática de recursos disponíveis, quanto em razão das suas próprias dificuldades, inclusive as relacionadas aos vínculos trabalhistas. Esses, muitas vezes, passam ao largo das mediações jurídicas definidas pela própria ordem liberal.

\section{Conclusão}

As reflexões desenvolvidas no presente artigo tratam sobre o Auxílio Emergencial, benefício financeiro concedido pelo governo federal e operado pela Caixa Econômica Federal a uma gama variada de destinatários, com vistas a viabilizar o enfrentamento da crise causada pela pandemia da Covid-19. Evidenciou-se, no texto, que tal crise se sobrepõe a um contexto socioeconômico já extremamente desfavorável, marcado pela deterioração dos indicadores de mercado de trabalho, de pobreza e de extrema pobreza, após as expressivas melhorias experimentadas entre o início dos anos 2000 e 2014. A partir de então, aliada a uma crise econômica, eclode uma crise político-institucional, culminando com o Golpe de 2016 e demarcando a vitória de um projeto ultraliberal e conservador. Esse, a pretexto de promover o ajuste fiscal, passou a pôr em xeque as mais importantes conquistas civilizatórias da sociedade brasileira nos mais variados campos das políticas públicas, especialmente no campo social.

Assim, se do ponto de vista imediato o Auxílio Emergencial é relevante para a sobrevivência das famílias e a dinamização das comunidades, considerando sua natureza, desvela os níveis de pobreza e desigualdade como marcas da sociedade brasileira no presente. Desnuda também o projeto político em andamento, que tem a crise ambiental e sanitária como reflexo desse projeto de sociedade em curso no país, cuja dinâmica se constitui desagregada de um modelo de justiça social baseado na ideia de solidariedade sistêmica.

Nesse sentido, ainda que os recursos repassados para os beneficiados não provoquem mudanças na situação de pobreza, trata-se de um espaço/tempo que estabelece coordenadas que permitem pensar sobre as condições objetivas de grandes massas populacionais no Brasil carentes de assistência, bem como sobre seus direitos e sobre o papel do Serviço Social e suas propostas construídas para o avanço do trabalho profissional.

É importante relembrar que o/a assistente social é parte das equipes de trabalho que se posicionam no campo da assistência social. Situa-se, pois, como todos os outros trabalhadores, como população assalariada; porém, considerando a dinâmica do capitalismo, pode vir a se constituir em superpopulação relativa, supérflua, na expectativa de ser aproveitada

${ }^{8}$ Esse tema pode ser ampliado com base nas reflexões de Antunes (2018), Carvalho (2014) e Santos (2007). 


\section{ReVIStg all paUt?}

\} AUXÍLIO EMERGENCIAL - SILVA, M. O. S.; SOUSA, S. M. P. S.; LIMA, V. F. S. A. \}

DOI: $10.12957 /$ REP.2021.60299

pelo capital em algum ciclo expansivo futuro. Portanto, seu trabalho guarda relação com os demandantes dos espaços de atendimento também porque são os mesmos direitos em refluxo no atual contexto brasileiro. 


\section{Referências}

ANTUNES, R. O privilégio da servidão: o novo proletariado de serviços na era digital. São Paulo: Boitempo, 2018.

CARVALHO, A. A precarização estrutural do trabalho na civilização do capital em crise: o precariado como enigma contemporâneo. Revista de Políticas Públicas, São Luís, n. esp., jul. 2014.

FALEIROS, V. P. O Serviço Social no cotidiano: fios e desafios. Serviço Social e Sociedade, São Paulo, n. 120, out./dez. 2014.

IBGE. Pesquisa nacional por amostra de domicílio contínua mensal: pesquisa básica 2001-2015. Rio de Janeiro, nov. 2015. Disponível em: https://sidra. ibge.gov.br/pesquisa/pnad/geral/pesquisa-basica. Acesso em: 1 ago. 2020. IBGE. Pesquisa nacional por amostra de domicílio contínua - Terceiro trimestre de 2017. Rio de Janeiro, 2017. Disponível em: https://biblio teca.ibge.gov.br/visualização/periodicos/2421/pnact_2017_3tri.pdf. Acesso em: 5 set. 2018.

IBGE. Síntese de indicadores sociais: rendimentos. Rio de Janeiro, 2020. Disponível em: https://www.ibge.gov.br/estatisticas/sociais/trabalho/9221sintese-de-indicadores-sociais.html. Acesso em: 1 ago. 2020.

IBRE. A crise econômica se intensifica no Brasil e no mundo, ainda sem saídas claras. Boletim Macro do FGV/IBRE, Rio de Janeiro, 2020. Disponível em:https://portalibre.fgv.br/data/files/BD/24/55/53/14CA1710199794F6 8904CBA8/BoletimMacrolbre_2004.pdf-. Acesso em: 1 ago. 2020.

KILDUFF, F.; SILVA, M. M. da. Tensões da política social brasileira: entre o aparato assistencial e a criminalização da questão social no Brasil. Revista Katálysis, Florianópolis, v. 22, n. 3, set./dez. 2019.

LIMA, V. F. S. de A. Editorial: a questão do neodesenvolvimento e as políticas públicas: o debate contemporâneo. Revista de Políticas Públicas, São Luís, v. 17, n. 2, jul./dez. 2013.

LIMA, V. F. S. A.; MORAES, G. B. P.; SILVA, R. T. C. A atual conjuntura de aprofundamento da precarização do trabalho no Brasil e no Maranhão e as recentes medidas de flexibilização das relações de trabalho. Boletim do Observatório Social e do Trabalho, São Luís, ano 6, n. 2, 2017. Disponível em:http://www.gaepp.ufma.br/boletim/index.php?option=com_content $\& v i e w=$ frontpage\&ltemid=79. Acesso em: 23 abr. 2018.

MORIN, E. Um festival de incerteza. Insurgências, 2020. Disponível em: https://www.insurgencia.org/blog/edgar-morin-um-festival-de-incerteza. Acesso em: 15 jun. 2020. 
NEGRI, F. L.; SANTOS, M. T.; KRÜGER, T. R. Atuação da/o assistente social em face da pandemia da Covid-19: orientações técnicas elaboradas pelo conjunto CFESS/CRESS, 2020. Disponível em: https://comitesuassccovid1 9.org/2020/08/15/artigo-a-atuacao-da-o-assistente-social-em-faceda-pandemia-da-covid19-orientacoes-tecnicas-elaboradas-pelo-conjuntocfess-cress/. Acesso em: 15 nov. 2020.

RAICHELIS, R. et al. (Org.). O Sistema Único de Assistência Social no Brasil: disputas e resistências em movimento. São Paulo: Cortez Editora, 2019.

RBRB. Sobre a renda básica. [2019?]. Disponível em: http://rendabasica. com.br/sobre-a-renda-basica/. Acesso em: 18 abr. 2020.

SANTOS, B. S. Para além do pensamento abissal: das linhas globais a uma ecologia de saberes. Novos estudos Cebrap, São Paulo, n. 79, nov. 2007. Disponível em: https://www.scielo.br/scielo.php?script=sci_arttext\&pid= S0101-33002007000300004. Acesso em: 15 nov. 2020.

SILVA, M. O. S. e et al. Do declínio ao acirramento da pobreza no Brasil nas duas primeiras décadas do século XXI: agravamento das desigualdades no contexto da Covid-19 e respostas do Estado brasileiro para proteção social. São Luís, 2020. Mimeo.

SILVA, M. O. S. e. O avanço do debate e a formulação de propostas de Programas de Transferência de Renda para a proteção social no contexto da pandemia da Covid-19. In: SIMPÓSIO INTERNACIONAL ESTADO, SOCIEDADE E POLÍTICAS PÚBLICAS, 2020, Teresina. Anais... Teresina: UFPI, 2020a.

SILVA, M. O. S. e. Prevalência da transferência monetária para proteção social no Brasil: o falseamento da concepção e da prática da renda básica. In: GONÇALVES, C. C.; DESTERRO, R. (Org.). Vulnerabilidades sociais em tem-po de pandemia. Rio de Janeiro: Lumen Juris, $2020 \mathrm{~b}$.

SILVA, M. O. S. e; LIMA, V. F. S. de A. The political and economic juncture in Brazil after the Lula and Dilma administrations: a step back in the direction of implantation of a Basic Income in Brazil. In: INTERNATIONAL CONFERENCE OF THE BASIC INCOME EARTH NETWORK, 17., 2017, Lisboa. Congress papers, Lisboa, 2017. Disponível em: https://basicincome.org/ congresses/. Acesso em: 20 abr. 2020.

SILVA, M. O. S. e; YAZBEK, M. C.; GIOVANNI, G. A política social brasileira no século XXI: a prevalência dos programas de transferência de renda. São Paulo: Cortez Editora, 2012.

SOUSA, S. M. P. S. S. A Contribuição da política de assistência social no momento atual da pandemia de Covid-19. In: SIMPÓSIO INTERNACIONAL ESTADO, SOCIEDADE E POLÍTICAS PÚBLICAS, 3, 2020, [S. I.]. Anais... [S. I.], 2020. 


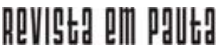

\} AUXÍLIO EMERGENCIAL - SILVA, M. O. S.; SOUSA, S. M. P. S.; LIMA, V. F. S. A. \}

DOI: $10.12957 /$ REP.2021.60299

TORRY, M. (Ed.). The pelgrave international handbook of basic income. London: Pelgrave Macmilian, 2019.

USP. Pandemia da Covid-19 cria novo grupo de vulneráveis: homens e mulheres brancas atuantes em serviços não essenciais. São Paulo, 2020. Disponível em: http://centrodametropole.ffich.usp.br/pt-br/noticia/ pandemia-da-covid-19-cria-novo-grupo-de-vulneraveis-homens-emulheres-brancos-atuantes-em. Acesso em: 3 jun. 2020.

YAZBEK, M. C.; FALEIROS, V. P. Aula 3 - Política social e profissão: fundamentos em debate. In: CORTEZ EDITORA. I Ciclo de debates dos fundamentos do Serviço Social - Interlocuções da profissão com o marxismo. 2020. Disponível em: https://www.youtube.com/watch?v=lqvZCa7gbeM. Acesso em: 5 nov. 2020.

DOI: $10.12957 /$ rep.2021.60299

Recebido em 27 de novembro de 2020.

Atualizado em 03 de maio de 2021.

Aprovado para publicação em 18 de dezembro de 2020.

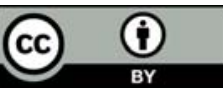

A Revista Em Pauta: Teoria Social e Realidade Contemporânea está licenciada com uma Licença Creative Commons Atribuição 4.0 Internacional. 